\title{
Investigation on the Combined Effect of VSC-based Sources and Synchronous Condensers under Grid Unbalanced Faults
}

\author{
Jia, Jundi; Yang, Guangya; Nielsen, Arne Hejde; Gevorgian, Vahan
}

Published in:

IEEE Transactions on Power Delivery

Link to article, DOI:

10.1109/TPWRD.2019.2914342

Publication date:

2019

Document Version

Peer reviewed version

Link back to DTU Orbit

Citation (APA):

Jia, J., Yang, G., Nielsen, A. H., \& Gevorgian, V. (2019). Investigation on the Combined Effect of VSC-based Sources and Synchronous Condensers under Grid Unbalanced Faults. IEEE Transactions on Power Delivery, 34(5), 1898-1908. https://doi.org/10.1109/TPWRD.2019.2914342

\section{General rights}

Copyright and moral rights for the publications made accessible in the public portal are retained by the authors and/or other copyright owners and it is a condition of accessing publications that users recognise and abide by the legal requirements associated with these rights.

- Users may download and print one copy of any publication from the public portal for the purpose of private study or research.

- You may not further distribute the material or use it for any profit-making activity or commercial gain

- You may freely distribute the URL identifying the publication in the public portal 


\title{
Investigation on the Combined Effect of VSC-based Sources and Synchronous Condensers under Grid Unbalanced Faults
}

\author{
Jundi Jia, Member, IEEE, Guangya Yang, Senior Member, IEEE, \\ Arne Hejde Nielsen, Senior Member, IEEE, and Vahan Gevorgian, Senior Member, IEEE
}

\begin{abstract}
The short circuit response of voltage source converters (VSCs) could be significantly different from that of synchronous condensers (SCs) under unbalanced faults. This paper investigates the combined effect of VSC-based sources and synchronous condensers under grid unbalanced faults considering two groups of VSC fault-ride-through (FRT) control strategies. It aims to provide an evaluation of the different control strategies and to explore the impact of equipping a synchronous condenser at the point of common coupling (PCC). By examining the combined short circuit currents, PCC voltages, DC-side voltages and system frequency responses, this study points out the merits and demerits of the examined control strategies; illustrates the benefits of synchronous condensers on mitigating the disadvantages of certain control strategies; and provides suggestions on selecting the control strategies for the VSC when incorporating a synchronous condenser at the PCC.
\end{abstract}

Index Terms-Converter; inertia; short circuit power; synchronous condensers; unbalanced faults.

\section{INTRODUCTION}

W HEN a grid experiences an unbalanced fault, the negative-sequence voltage appearing at the PCC can propagate into the control system of a VSC and affects its performances. If the negative-sequence components are not controlled properly, undesirable behaviors such AC voltage and current distortions can be observed. Therefore, a variety of control strategies based on symmetrical component theory and instantaneous power theory [1] have been proposed to improve the FRT capability of VSCs under grid unbalanced faults [2]-[5]. For a voltage-oriented current-controlled VSC system, these control strategies mainly deal with the generation of current references for the inner current controllers. In spite of various control objectives, most of the proposed control strategies can be categorized by flexible oscillating power control (FOPC) and flexible positive- and negative-sequence power control (FPNSPC) in a general way [4]. With different control strategies, the short circuit response of VSCs under

Manuscript received May 30, 2018; revised December 30, 2018 and March 10, 2019; accepted April 26, 2019. The work is supported by Danish ForskEL project "Synchronous Condensers Application in Low Inertia Systems (SCAPP)", grant no. 12196, administrated by Energinet.

J.Jia, G.Yang and A.H.Nielsen is with the Center for Electric Power and Energy, the Department of Electrical Engineering, Technical University of Denmark, Kongens Lyngby DK-2800, Denmark e-mail: (junjia@elektro.dtu.dk; gyy@elektro.dtu.dk; ahn@elektro.dtu.dk).

V. Gevorgian is with the National Wind Technology Center, National Renewable Energy Laboratory, Golden, CO 80401, USA e-mail: (vahan.gevorgian@nrel.gov). unbalanced faults can be significantly different from each other and from that of synchronous sources. However, the existing grid codes on VSC-based sources generally lack informative statements specifically for unbalanced faults and hence how a VSC should be controlled under grid unbalanced faults is still under open discussion.

On the other hand, with proliferated renewable energy integration and gradual retirement of conventional generation units, modern power systems are currently undergoing significant changes in the generation mix and facing a variety of challenges. Conventional generation units usually consist of large synchronous generators, while renewable-based generations and high-voltage direct current (HVDC) transmission systems typically interface with the grids through power converters. Firstly, synchronous generators are natural voltage sources, which are able to provide a large amount short circuit current under grid fault conditions. This current is of great importance to activate protective relays. However, due to the limited overload capacities of semiconductors, power converters can only provide a limited amount of short circuit current. Secondly, as strong voltage sources, synchronous generators help stabilize voltage changes and enhance the connectivity of power electronic devices. In contrast, power converters behave more like current sources and operate under the presumption of having "strong" grids. In addition, synchronous generators have large rotating shafts and provide inertia to the system to counter frequency deviations. Nevertheless, power converters do not have rotating shafts directly coupled with the grids. Therefore, the transition to a converter-based power system from a synchronous-generator-based one tends to reduce the system short circuit current level, the system strength, as well as the system voltage and frequency stability.

Given the above-mentioned challenges, synchronous condensers (SCs) have gained increasing attention in recent years as it can serve as a potential solution as a single device. For example, two 225 Mvar synchronous condensers for Tegala substation have been committed to increase short circuit current level, voltage support capability, and system inertia in California, USA [6]. Several studies [7]-[13] have also shown the benefits of SCs on the short circuit current contribution, improved voltage regulation and voltage stability, and frequency stability enhancement. Even though conventional power plants can be refurbished into synchronous condensers as a costeffective approach [14], [15], the conventional power plants may not always serve as the best locations for SCs and newly- 
installed ones can be anticipated. In [15]-[17], the optimal allocation of synchronous condensers is of a interest and the results have indicated that there is a need of installing new SCs at the PCCs of HVDC systems or wind farms in future power systems. Therefore, it is necessary to investigate the combined effect of VSC-based sources and synchronous condensers taking different VSC control strategies into considerations under unbalanced faults. This has not been studied in the literature to the best of the authors' knowledge.

This paper investigates the combined effect of a VSC-based HVDC system and an SC under grid unbalanced faults when an SC is equipped at the PCC. Considering the converter current limit in each phase, the investigation helps to evaluate the two generalized groups of the VSC control strategies (FOPC and FPNSPC) in a unified manner and explore the impacts of incorporating an SC with a VSC-based source on the system behaviors under unbalanced faults. Besides pointing out the pros and cons of different control strategies, this study illustrates the benefits of SCs on mitigating the disadvantages of certain control strategies, providing suggestions on selecting the control strategies for the VSC when incorporating an SC at the PCC.

The rest of the paper is organized as follows. Section II briefly presents the two generalized groups of VSC control strategies under unbalanced faults and discusses their relationship. In Section III, synchronous condensers and their benefits are shortly introduced. The combined effect of a VSC-HVDC system and a synchronous condenser are investigated and analyzed through various case studies in Section IV. Finally, Section V provides the conclusions.

\section{VSC CONTROL STRATEGIES UNDER GRID UNBALANCED FAULTS}

For a three-phase three-wire voltage source converter (zerosequence components are neglected), the instantaneous active and reactive powers at the PCC can be expressed as [18]:

$$
\begin{aligned}
& p=\underbrace{\overbrace{\mathbf{v}^{+} \cdot \mathbf{i}_{P}^{+}}^{P^{+}}+\overbrace{\mathbf{v}^{-} \cdot \mathbf{i}_{P}^{-}}^{P^{-}}}_{\bar{P}}+\underbrace{\mathbf{v}^{+} \cdot \mathbf{i}_{P}^{-}+\mathbf{v}^{-} \cdot \mathbf{i}_{P}^{+}}_{\widetilde{P}} \\
& q=\underbrace{\overbrace{\mathbf{v}_{\perp}^{+} \cdot \mathbf{i}_{Q}^{+}}^{Q^{+}}+\overbrace{\mathbf{v}_{\perp}^{-} \cdot \mathbf{i}_{Q}^{-}}^{Q^{-}}}_{\bar{Q}}+\underbrace{\mathbf{v}_{\perp}^{+} \cdot \mathbf{i}_{Q}^{-}+\mathbf{v}_{\perp}^{-} \cdot \mathbf{i}_{Q}^{+}}_{\widetilde{Q}}
\end{aligned}
$$

where $\mathbf{v}=\left[\begin{array}{lll}v_{a} & v_{b} & v_{c}\end{array}\right]^{T}$ is the voltage vector at the PCC; $\mathbf{i}=\left[\begin{array}{lll}i_{a} & i_{b} & i_{c}\end{array}\right]^{T}$ is the current vector consisting of active current $\mathbf{i}_{P}$ and reactive current $\mathbf{i}_{Q}$; the subscript " $\perp$ " refers to an orthogonal version $\left(90^{\circ}\right.$ delayed) of the original vector; the operator "." represents the dot product of vectors; the superscripts "+" and "-" denote the positive- and negativesequence components. According to (1) and (2), the instantaneous power contains constant terms $(\bar{P}, \bar{Q})$ and oscillating terms $(\widetilde{P}, \widetilde{Q})$. As the average value of each oscillating term is zero, the power delivery is satisfied by constant terms that consist of positive-sequence powers $\left(P^{+}, Q^{+}\right)$and negativesequence powers $\left(P^{-}, Q^{-}\right)$.
The control strategy of VSCs under unbalanced faults mainly depends on how current references are formulated. Even though the current references are generated based on various objectives and can be expressed in different ways, a common feature is that these control strategies are able to provide positive- and negative-sequence current simultaneously. In this paper, two groups of current references expressed in a more general form are considered.

\section{A. Group 1-Flexible Oscillating Power Control (FOPC)}

In [19], the current references under unbalanced faults are formulated in a way that the amplitudes of the oscillating powers $\widetilde{P}$ and $\widetilde{Q}$ can be directly controlled with :

$$
\begin{aligned}
& \mathbf{i}^{+}=\frac{P^{r e f}}{\left|\mathbf{v}^{+}\right|^{2}+x\left|\mathbf{v}^{-}\right|^{2}} \mathbf{v}^{+}+\frac{Q^{\text {ref }}}{\left|\mathbf{v}^{+}\right|^{2}+y\left|\mathbf{v}^{-}\right|^{2}} \mathbf{v}_{\perp}^{+} \\
& \mathbf{i}^{-}=\frac{x P^{r e f}}{\left|\mathbf{v}^{+}\right|^{2}+x\left|\mathbf{v}^{-}\right|^{2}} \mathbf{v}^{-}+\frac{y Q^{r e f}}{\left|\mathbf{v}^{+}\right|^{2}+y\left|\mathbf{v}^{-}\right|^{2}} \mathbf{v}_{\perp}^{-}
\end{aligned}
$$

where $x$ and $y$ are the factors that change the formation of the current references and hence determine the control strategy; $P^{r e f}$ and $Q^{r e f}$ are the references of active and reactive powers. If the relationship between $x$ and $y$ is chosen as $x=-y=k(-1 \leq k \leq 1)$, three most representative control strategies can be obtained. They are constant active power control (oscillation-free active power from the VSC with $k=-1$ ), constant reactive power control (oscillationfree reactive power from the VSC with $k=1$ ) and balanced current control (only positive-sequence current provision from the VSC with $k=0$ ).

\section{B. Group 2-Flexible Positive- and Negative-sequence Power Control (FPNSPC)}

In [18], the current references under unbalanced faults can be formulated in a way the relative amount between the positive- and negative-sequence powers can be directly controlled with:

$$
\begin{aligned}
& \mathbf{i}^{+}=a \frac{P^{r e f}}{\left|\mathbf{v}^{+}\right|^{2}} \mathbf{v}^{+}+c \frac{Q^{r e f}}{\left|\mathbf{v}^{+}\right|^{2}} \mathbf{v}_{\perp}^{+} \\
& \mathbf{i}^{-}=b \frac{P^{r e f}}{\left|\mathbf{v}^{-}\right|^{2}} \mathbf{v}^{-}+d \frac{Q^{r e f}}{\left|\mathbf{v}^{-}\right|^{2}} \mathbf{v}_{\perp}^{-}
\end{aligned}
$$

where $a, b, c$ and $d$ are the four factors that determine the control strategy. By substituting (5) and (6) into (1) and (2), there are:

$$
\begin{aligned}
& p=\overbrace{a P^{r e f}}^{P^{+}}+\overbrace{b P^{r e f}}^{P^{-}}+\widetilde{P} \\
& q=\overbrace{c Q^{r e f}}^{Q^{+}}+\overbrace{d Q^{r e f}}^{Q^{-}}+\widetilde{Q}
\end{aligned}
$$

As the average value of the oscillating power terms is zero, the relationships $a+b=1$ and $c+d=1$ have to be satisfied so that the output powers meet their references. This indicates that two factors $a$ and $c$, which represents the share of $P^{+}$and $Q^{+}$ respectively, can be used to characterize the control strategy. Therefore, different control strategies can be considered as different combinations of the sequence output powers. 


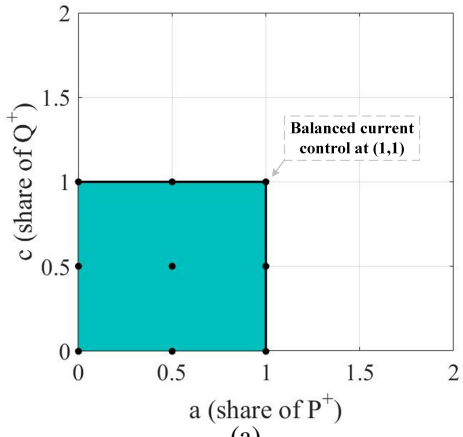

(a)

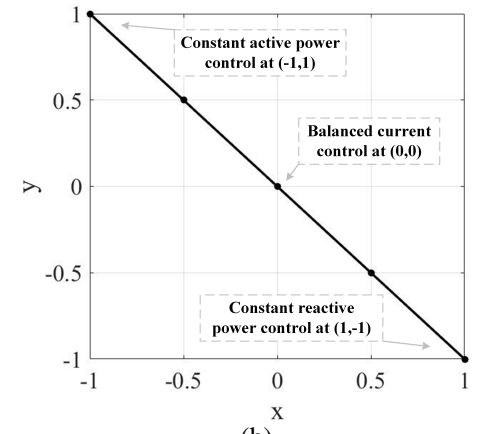

(b)

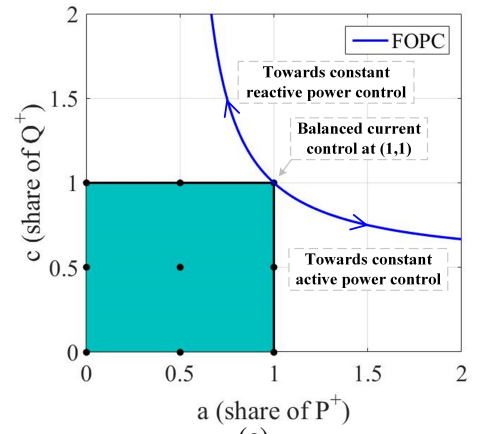

(c)

Fig. 1. Control strategy factor planes for (a) FPNSPC. (b) FOPC. (c) FPNSPC with FOPC.

\section{Relationship between FOPC and FPNSPC}

In spite of different expressions, the current references of these two groups are indeed interchangeable. For example, if the control strategy factors $a$ and $c$ in (5) and (6) satisfy:

$$
\begin{aligned}
& 1 / a+1 / c=2 \\
& a, c \in\left[\frac{\left|\mathbf{v}^{+}\right|^{2}}{\left|\mathbf{v}^{+}\right|^{2}+\left|\mathbf{v}^{-}\right|^{2}}, \frac{\left|\mathbf{v}^{+}\right|^{2}}{\left|\mathbf{v}^{+}\right|^{2}-\left|\mathbf{v}^{-}\right|^{2}}\right]
\end{aligned}
$$

FPNSPC becomes equivalent to FOPC with $x=-y=k$ $(-1 \leq k \leq 1)$. It is worth mentioning that constant active power control is achieved with:

$$
a=\frac{\left|\mathbf{v}^{+}\right|^{2}}{\left|\mathbf{v}^{+}\right|^{2}-\left|\mathbf{v}^{-}\right|^{2}}, c=\frac{\left|\mathbf{v}^{+}\right|^{2}}{\left|\mathbf{v}^{+}\right|^{2}+\left|\mathbf{v}^{-}\right|^{2}}
$$

while constant reactive power control is achieved by flipping the values of $a$ and $c$ in (11). As indicated in (11), the share of the positive-sequence powers are not directly controlled in FOPC, but depends on the fault conditions since $a$ and $c$ are functions of the PCC voltages.

To illustrate the above relationship, Fig. 1(a) is used to represent the $a-c$ plane for FPNSPC, where the values of $a$ and $c$ in (5) and (6) can be freely chosen on this plane; while Fig. 1(b) is for FOPC, but the values of $x$ and $y$ in (3) and (4) are restricted to the black line $(x=-y)$. If FOPC is expressed using the share of the positive-sequence powers, the black line in Fig. 1(b) will be interpreted as (9) (the blue line in Fig. $1(c)$ ). This means that if $a$ and $c$ in (5) and (6) are restricted to the blue line in Fig. 1(c), FPNSPC will be equivalent to FOPC. Therefore, a common feature of the different control strategies is the flowing of active and reactive powers in both positive- and negative-sequence networks. With $0<c<1$, the VSC provides $Q^{+}$and $Q^{-}$simultaneously under unbalacned faults. If there is $c>1$ (e.g. control strategy moves from balanced current control to constant reactive power control), $d$ becomes negative since $c+d=1$ is always matained. This means, the VSC will absorb $Q^{-}$and provide $Q^{+}$at the same time. Similarly, the VSC begins to absorb $P^{-}$with $a>1$ (e.g. control strategy moves from balanced current control to constant active power control).

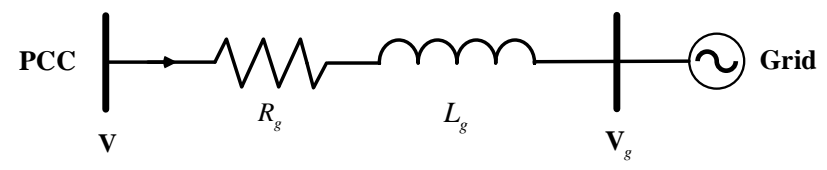

Fig. 2. A simplified power system as seen from the PCC

\section{Voltage Support Concept}

Figure 2 illustrates a simplified power system as seen from the PCC. The mathematical relationship between the PCC voltage $\mathbf{v}$ and grid voltage $\mathbf{v}_{\mathbf{g}}$ can be expressed by:

$$
\mathbf{v}=\mathbf{v}_{\mathbf{g}}+R_{g} \mathbf{i}+L_{g} \frac{d \mathbf{i}}{d t}
$$

If the grid resistance is ignored, (12) can be further decomposed into (13)-(14) in the stationary reference frame:

$$
\begin{aligned}
& v_{\alpha}=v_{g \alpha}+L_{g} \frac{d i_{\alpha}}{d t} \\
& v_{\beta}=v_{g \beta}+L_{g} \frac{d i_{\beta}}{d t}
\end{aligned}
$$

By decomposing the voltage and current in the stationary frame into symmetrical components, (13)-(14) can be expressed by:

$$
\begin{array}{r}
\sqrt{3} V^{+} \sin \left(\omega t+\varphi_{+}\right)+\sqrt{3} V^{-} \sin \left(\omega t+\varphi_{-}\right)= \\
\sqrt{3} V_{g}^{+} \sin \left(\omega t+\varphi_{g+}\right)+\sqrt{3} V_{g}^{-} \sin \left(\omega t+\varphi_{g-}\right)+ \\
\omega L_{g} \sqrt{3} I^{+} \cos \left(\omega t+\delta_{+}\right)+\omega L_{g} \sqrt{3} I^{-} \cos \left(\omega t+\delta_{-}\right) \\
-\sqrt{3} V^{+} \cos \left(\omega t+\varphi_{+}\right)+\sqrt{3} V^{-} \cos \left(\omega t+\varphi_{-}\right)= \\
-\sqrt{3} V_{g}^{+} \cos \left(\omega t+\varphi_{g+}\right)+\sqrt{3} V_{g}^{-} \cos \left(\omega t+\varphi_{g-}\right)+ \\
\omega L_{g} \sqrt{3} I^{+} \sin \left(\omega t+\delta_{+}\right)-\omega L_{g} \sqrt{3} I^{-} \sin \left(\omega t+\delta_{-}\right)
\end{array}
$$

where $V^{+}$and $V^{-}$are the root mean square (RMS) values of the sequence voltages; $\phi_{+}$and $\phi_{-}$are the corresponding phase angles for the voltages; $I^{+}$and $I^{-}$are the RMS values of the sequence currents; $\delta_{+}$and $\delta_{-}$are the corresponding phase angles for the currents. Next, by adding (15) to (16) on both sides of the equation, there is:

$$
\begin{array}{r}
V^{+}\left[\sin \left(\omega t+\varphi_{+}-\frac{\pi}{4}\right)\right]+V^{-}\left[\cos \left(\omega t+\varphi_{-}-\frac{\pi}{4}\right)\right]= \\
V_{g}^{+}\left[\sin \left(\omega t+\varphi_{g+}-\frac{\pi}{4}\right)\right]+V_{g}^{-}\left[\cos \left(\omega t+\varphi_{g-}-\frac{\pi}{4}\right)\right] \\
-\omega L_{g} I^{+}\left[\sin \left(\omega t+\delta_{+}-\frac{3 \pi}{4}\right)\right]-\omega L_{g} I^{-}\left[\cos \left(\omega t+\delta_{-}-\frac{3 \pi}{4}\right)\right]
\end{array}
$$


TABLE I

IMPACT OF SEQUENCE REACTIVE POWER ON THE PCC VOLTAGE

\begin{tabular}{cc}
\hline \hline Sequence reactive power & Effect \\
\hline Provide $Q^{+}\left(Q^{+}>0\right)$ & Increase $\left|\mathbf{v}^{+}\right|$ \\
Provide $Q^{-}\left(Q^{-}>0\right)$ & Decrease $\left|\mathbf{v}^{-}\right|$ \\
Absorb $Q^{+}\left(Q^{+}<0\right)$ & Decrease $\left|\mathbf{v}^{+}\right|$ \\
Absorb $Q^{-}\left(Q^{-}<0\right)$ & Increase $\left|\mathbf{v}^{-}\right|$ \\
\hline \hline
\end{tabular}

If only reactive current is injected from the PCC, the angle difference between the sequence voltage at the PCC and the sequence current is given by:

$$
\begin{aligned}
& \varphi_{+}-\delta_{+}=\frac{\pi}{2} \\
& \varphi_{-}-\delta_{-}=-\frac{\pi}{2}
\end{aligned}
$$

With (18)-(19) substituted into (17), the different terms on both sides of (17) can be categorized in terms of sequence components:

$$
\begin{aligned}
V^{+}\left[\sin \left(\omega t+\varphi_{+}-\frac{\pi}{4}\right)\right] & =V_{g}^{+}\left[\sin \left(\omega t+\varphi_{g+}-\frac{\pi}{4}\right)\right. \\
+ & \omega L_{g} I^{+}\left[\sin \left(\omega t+\varphi_{+}-\frac{\pi}{4}\right)\right] \\
V^{-}\left[\cos \left(\omega t+\varphi_{-}-\frac{\pi}{4}\right)\right] & =V_{g}^{-}\left[\cos \left(\omega t+\varphi_{g-}-\frac{\pi}{4}\right)\right] \\
& -\omega L_{g} I^{-}\left[\cos \left(\omega t+\varphi_{-}-\frac{\pi}{4}\right)\right]
\end{aligned}
$$

Finally, with only reactive current injected, all the terms within the same sequence are in phase with each other. As a result, there are:

$$
\begin{aligned}
& V^{+}=V_{g}^{+}+\omega L_{g} I^{+} \\
& V^{-}=V_{g}^{-}-\omega L_{g} I^{-}
\end{aligned}
$$

which indicates that $Q^{+}$and $Q^{-}$have a direct impact on the sequence voltages for an inductive grid. Table I summarizes the impact of sequence reactive power on the PCC voltage for an inductive grid. However, as indicated by (22)-(23), $P^{+}$and $P^{-}$have less effect on grid voltages for an inductive grid.

On the other hand, if $L_{g}$ is ignored rather than $R_{g}$ in Fig. 2 and only active current is injected at the PCC, (24)-(25) can be obtained by repeating the procedure (12)-(21):

$$
\begin{aligned}
& V^{+}=V_{g}^{+}+R_{g} I^{+} \\
& V^{-}=V_{g}^{-}+R_{g} I^{-}
\end{aligned}
$$

which indicates the injection of $P^{+}$and $P^{-}$will increase the positive- and negative-sequence voltages respectively.

\section{SYNCHRONOUS CONDENSERS}

A synchronous condenser (SC) is essentially a common synchronous machine that runs idle without any connected load at the drive end [11]. It can supply or absorb reactive power by varying its field current to provide voltage support dynamically like a synchronous generator (SG). For short circuit analysis, both SC and SG act as voltage sources, whose voltages are induced by the rotating magnetic field, behind an impedance. The impedance varies with time and the corresponding fault
TABLE II

The EXAMined CONTROL STRATEgies

\begin{tabular}{ccc}
\hline \hline & FOPC (with (3) and (4)) & FPNCPC (with (5) and (6)) \\
\hline $\begin{array}{c}\text { Control } \\
\text { strategy } \\
\text { factors }\end{array}$ & $\begin{array}{c}x=-y=k= \\
\{ \pm 1, \pm 0.5,0\}\end{array}$ & $\begin{array}{c}a=\{1,0.5,0\} \\
c=\{1,0.5,0\}\end{array}$ \\
\hline $\begin{array}{c}\text { Total } \\
\text { scenarios }\end{array}$ & 5 & $3 \times 3=9$ \\
\hline \hline
\end{tabular}
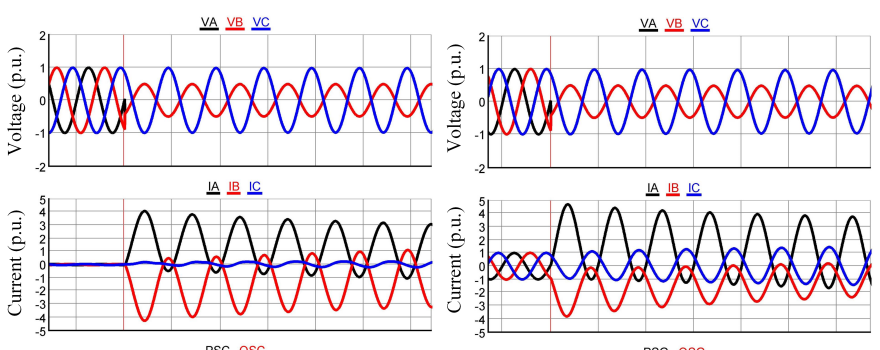

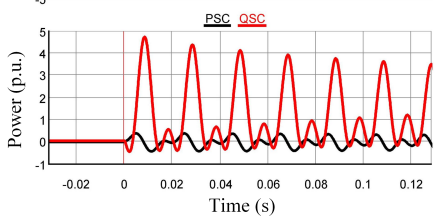

(a)

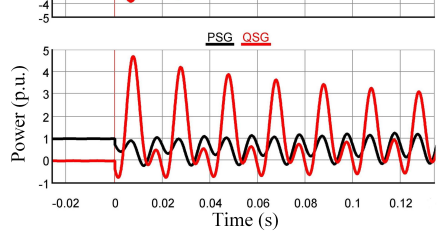

(b)
Fig. 3. Short circuit behaviour of synchronous sources subject to A-B fault. (a) Synchronous condenser. (b) Synchronous generator.

current can be classified into three characteristic periods: subtransient, transient and steady stages. Under grid unbalanced faults, SC and SG can naturally provide positive- and negativesequence short circuit current and the reactive power consists both positive- and negative-sequence components [20]. The characteristics (magnitudes and phases) of the short circuit current from SC and SG mainly depends on the sub-transient, transient impedances and the fault characteristics. Figure 3 gives an example illustrating the short circuit behavior of an SC and an SG (with the same parameters) subject to a phase A-B fault. Prior to the fault, both SC and SG are excited to exchange zero reactive power with the grid. During the fault, the short circuit currents in the faulty phases are with the same order in magnitudes. The currents in phase $\mathrm{A}$ and phase $\mathrm{B}$ are almost $180^{\circ}$ out of phase. As a synchronous machine, SC provides a large amount of reactive power during the short circuit, giving a higher short-term over-current capability compared to VSCs. The difference in phase C current is due to the fact that $\mathrm{SC}$ cannot deliver sustaining active power.

Since the $\mathrm{SC}$ is a rotating device, it can provide inertia for the system resulting its active power exchange with the grid during the transients [see Fig. 3(a)]. When there is a frequency deviation, kinetic energy can either be released from or stored in the rotating mass so that the power system frequency changes are alleviated. For example, when there is a generation trip, synchronous condensers will release the rotational energy as active power to counter the system frequency drop. Therefore, frequency stability enhancement is another advantage of using synchronous condensers, especially for future converter-dominated power systems. 


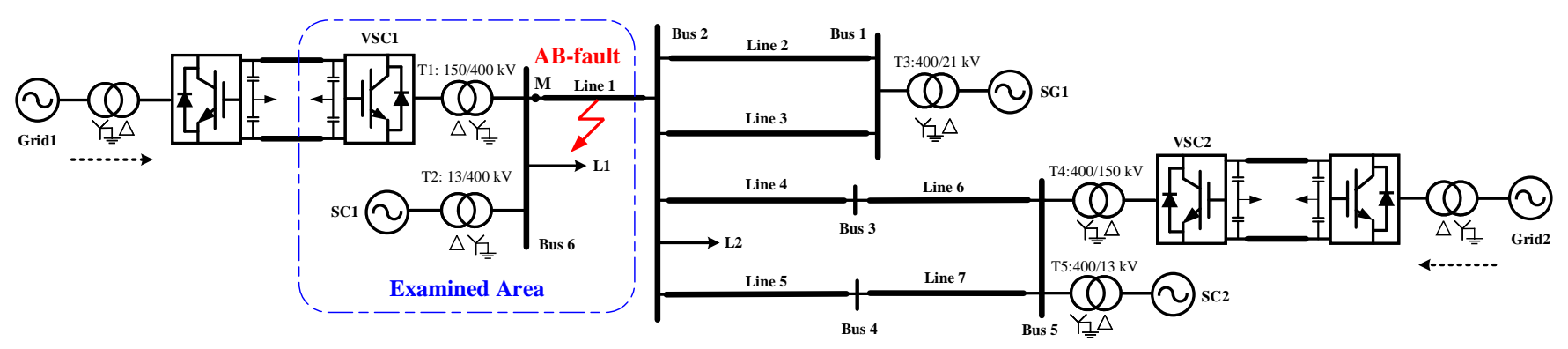

Fig. 4. Single-line diagram of the studied $400 \mathrm{kV}$ system

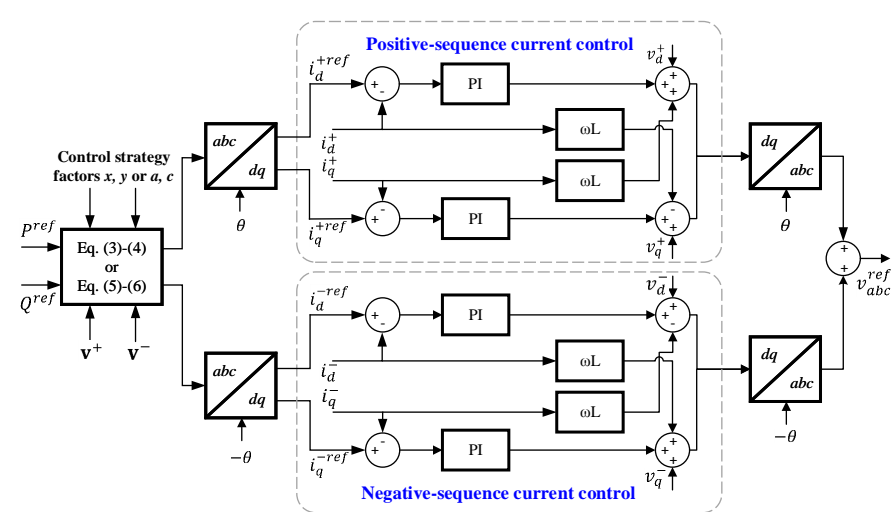

Fig. 5. Configuration of current control for VSC station during grid unbalanced faults

\section{CAse Studies}

\section{A. System Overview}

The investigations use a detailed electromagnetic transient (EMT) model in Real Time Digital Simulator (RTDS). All the simulation results are exported from RTDS to MATLAB and replotted for comparisons. The single-line diagram of the studied system is given in Fig. 4. A synchronous generator SG1 is connected to bus 1 (slack bus). Two VSC-HVDC systems are connected to bus 5 and 6 respectively, where synchronous condensers $\mathrm{SC} 1$ and $\mathrm{SC} 2$ are also equipped on each bus. The HVDC sysetms deploy two-level converters and interface with the grid through $\Delta /$ Y-g connected transformers. Based on [21], both VSC-HVDC systems are equipped with a dynamic braking resistor on the DC-side in order to drain the excess electrostatic energy from the DC link into the resistor under fault conditions. It is assumed that the active power from the other side of each VSC-HVDC system remains constant at all time. In this study, the focus is given to the marked area around bus 6 . In order to examine different scenarios, SC1 can either be disconnected from the grid or has a capacity of 50/150/250 Mvar. The control strategy factors of VSC1 can be varied according to Table. II. The remaining power system has the same condition in all the scenarios, where the capacity of SC2 is fixed at 160 Mvar and the control strategy of VSC2 is fixed at balanced current control under unbalanced faults. Figure 5 presents the configuration of the current control for VSCs during grid unbalanced faults, illustrating how current references (3)-(6) are deployed. The rest of the control system is not shown here for brevity. The short circuit ratio at bus 6 is approximately 4.0 when SC1 is disconnected from the
TABLE III

PARAMETERS OF THE STUdiEd SYSTEM

\begin{tabular}{cccc}
\hline \hline & $\begin{array}{c}\text { Rated power } \\
{[\mathrm{MVA}]}\end{array}$ & $\begin{array}{c}\text { Pre-fault active } \\
\text { power }[\mathrm{MW}]\end{array}$ & $\begin{array}{c}\text { Inertia Constant } \\
{[\mathrm{MWs} / \mathrm{MVA}]}\end{array}$ \\
\hline $\mathrm{SG}$ & 600 & 200 & 5.00 \\
$\mathrm{SC} 1$ & $50 / 150 / 250$ & - & 2.18 \\
$\mathrm{SC} 2$ & 160 & - & 2.18 \\
$\mathrm{VSC} 1$ & 500 & 500 & - \\
$\mathrm{VSC} 2$ & 500 & 350 & - \\
\hline \hline
\end{tabular}

grid, and 5.8 when a 250 Mvar SC1 is connected. In order to guarantee identical power flow results, $\mathrm{SC} 1$ is excited to exchange no reactive power with the grid in the steady state. Prior to the fault, VSC1 and VSC2 operate at unity power factor. Each load consumes $500 \mathrm{MW}$ active power and 100 Mvar reactive power. The ratings and pre-fault conditions of the machines and HVDCs are summarized in Table. III. More details of the system are given in the Appendix.

With limited semiconductor overload capabilities, the current flowing through power electronic devices should be restricted in each phase. In this paper, a 1 p.u. current limit is imposed for both VSC-HVDC converter stations using the current ellipse theory presented in [18] for each individual phase. In following simulations, a solid A-B fault occurring in the middle of line $6-2$ is initiated when the phase A voltage of bus 6 crosses zero from a negative to a positive value, which corresponds to the zero time instant. It is assumed that VSC1 and VSC2 stations prioritize reactive power injection under fault conditions. The reactive power reference is generated using $Q_{\text {ref }}=\left|\mathbf{v}^{+}\right| \cdot I_{Q}$, where the value of $I_{Q}$ is obtained from [22] and can be expressed by $I_{Q}=-2.5\left|\mathbf{v}^{+}\right|+2.25(0 \leq$ $\left.I_{Q} \leq 1\right)$.

\section{B. Short Circuit Current}

This case study investigates the characteristics of the combined short circuit current from VSC1 and SC1. With the control strategy factors of VSC1 (deploying FOPC) fixed, the capacity of $\mathrm{SC} 1$ is varied from 0 ( $\mathrm{SC} 1$ is disconnected from the grid) to 250 Mvar. The corresponding combined short circuit currents in phase $\mathrm{A}$ and phase $\mathrm{B}$ measured at point $\mathrm{M}$ are compared in Fig. 6 with different scenarios. When SC1 is not present (no SC), the phase relationship of the currents in phase A and phase B shifts from nearly $180^{\circ}$ out of phase (Fig. 6(a)) to almost in phase (Fig. 6(d)) with the control strategy moving from constant active power control $(k=-1)$ 

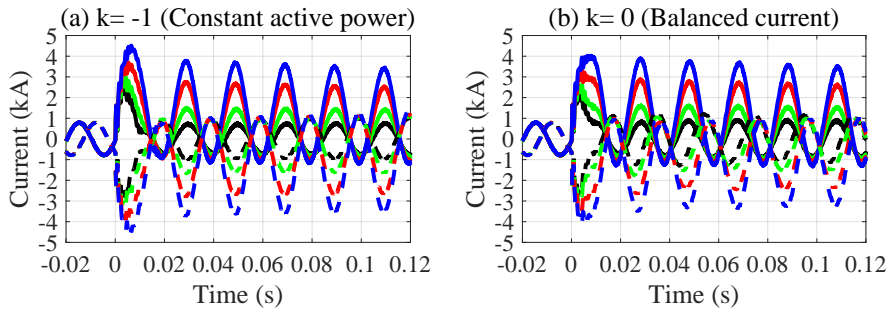

(c) $\mathrm{k}=-0.5$
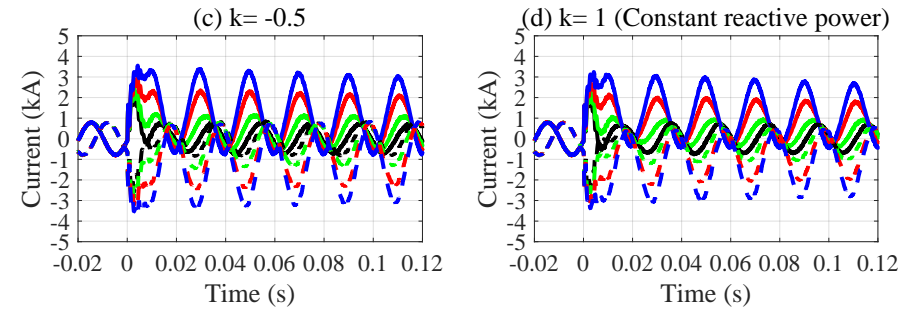

no SC phase A SC150 phase A - - no SC phase B - SC150 phase B

Fig. 6. Comparisons on the combined short circuit currents measured at $\mathrm{M}$ under different capacities of SC1. (VSC1 deploys FOPC; solid curve: phase A current; dashed curve: phase B current)
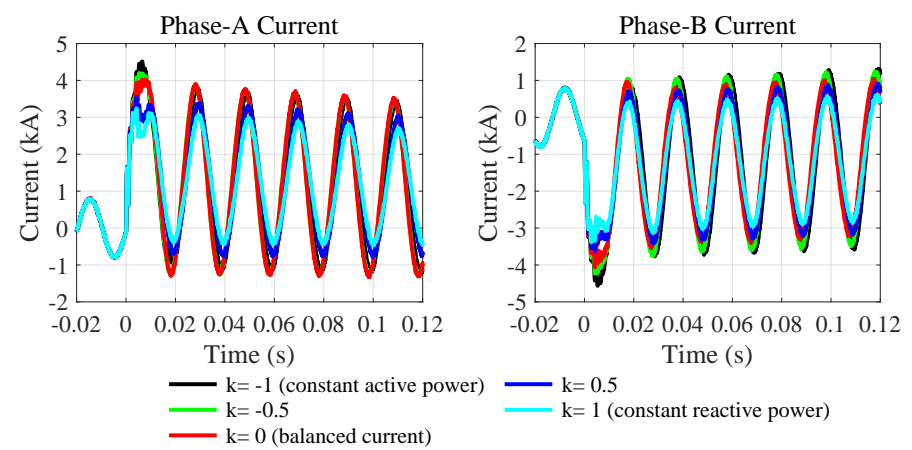

Fig. 7. Comparisons on the combined short circuit currents measured at $\mathrm{M}$ with different VSC1 (deploying FOPC) control strategies. (SC1: 250 Mvar)

to constant reactive power control $(k=1)$. The application of SC1 helps to increase the short circuit current level but this advantage is gradually deteriorated with $k$ changing from -1 to 1 . In the worst case with $k=1$, the application of a 50 Mvar SC1 has almost no improvement on the amplitude of the phase A current (by comparing "SC50 phase A" with "no SC phase A" in Fig. 6(d)). This is due to the fact that there is a phase difference between the short circuit current provided by VSC1 and $\mathrm{SC} 1$. The phases of the short circuit current from VSC1 are mainly affected by its control strategy while those from $\mathrm{SC} 1$ are mainly consistent with a certain type of unbalanced faults. Therefore, this difference could cause the currents to cancel each other to some extent. To illustrate this effect, Fig. 7 compares the combined short circuit current under different VSC1 control strategies using FOPC when SC1 has a capacity of 250 Mvar. It can be observed from Fig. 7 that the currents have relatively lower amplitudes with $k>0$ than other scenarios. This indicates that, with $k>0$, a higher capacity of $\mathrm{SC} 1$ is needed to achieve the same short circuit level as with $-1 \leq k \leq 0$ for FOPC.

The same investigation is repeated when VSC1 deploys FPNSPC with the different control strategy factors specified in Table. II. In this case, the current cancellation issue is not as significant as FOPC with $k>0$. The combined short
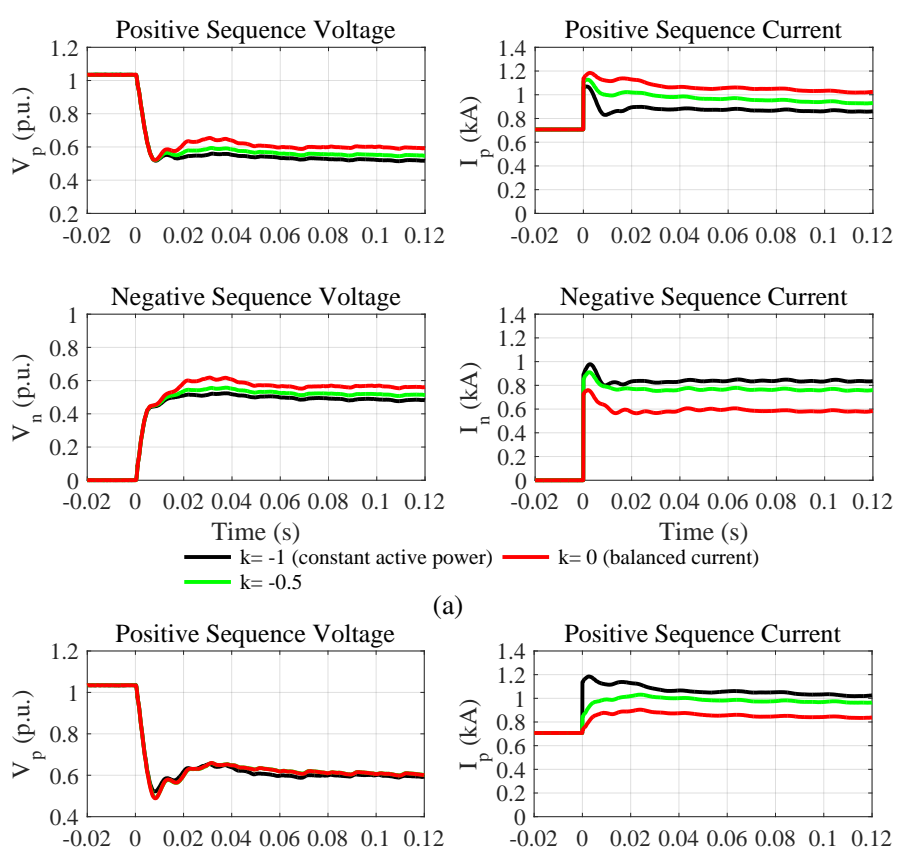

(a)
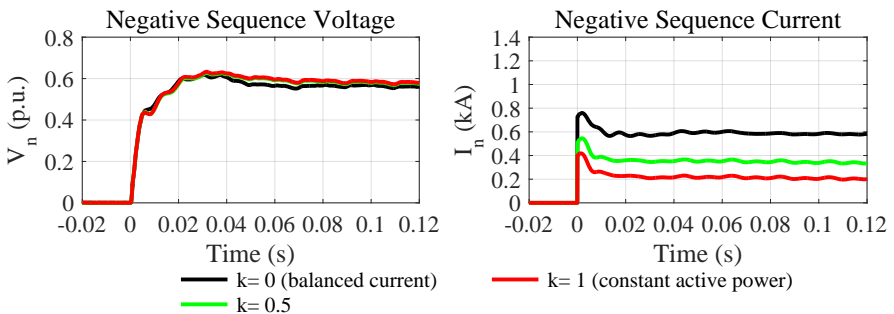

(b)

Fig. 8. Comparisons on the sequence voltages at the PCC (bus 6) and sequence currents measured at $\mathrm{M}$ under different VSC1 (deploying FOPC) control strategies. (SC1: 250 Mvar) (a): $-1 \leq k \leq 0$. (b): $0 \leq k \leq 1$

circuit current level in all the examined scenarios of FPNSPC can be increased with a 50 Mvar SC1 and the values of $a$ (share of $P^{+}$) and $c$ (share of $Q^{+}$) have less effect on the amplitudes of the combined short circuit current. The corresponding combined short circuit currents under different capacities of SC1 are similar to Fig. 6(b).

With converter current restricted in each phase, the short circuit current level drops significantly when it is only provided by a VSC. Among all the examined control strategies, it is not recommended to use FOPC with $0<x=-y=k \leq 1$ (absorbing $Q^{-}$) together with a SC. FOPC with $0<k \leq 1$ requires a higher capacity of SC to achieve the same short circuit current level as the other control strategies. This deteriorates the advantage of SC and might pose threats to the reliability of protection systems.

\section{PCC voltage}

Firstly, the effect of the VSC1 control strategies on the PCC (bus 6) voltage is investigated. Given a certain capacity of SC1, the control strategy factors of VSC1 are varied according to Table II. For example, with an SC1 of 250 Mvar, Fig. 8 and Fig. 9 compare the sequence voltages of the PCC and the sequence currents measured at point $\mathrm{M}$ under different control strategies with FOPC and FPNSPC respectively. 

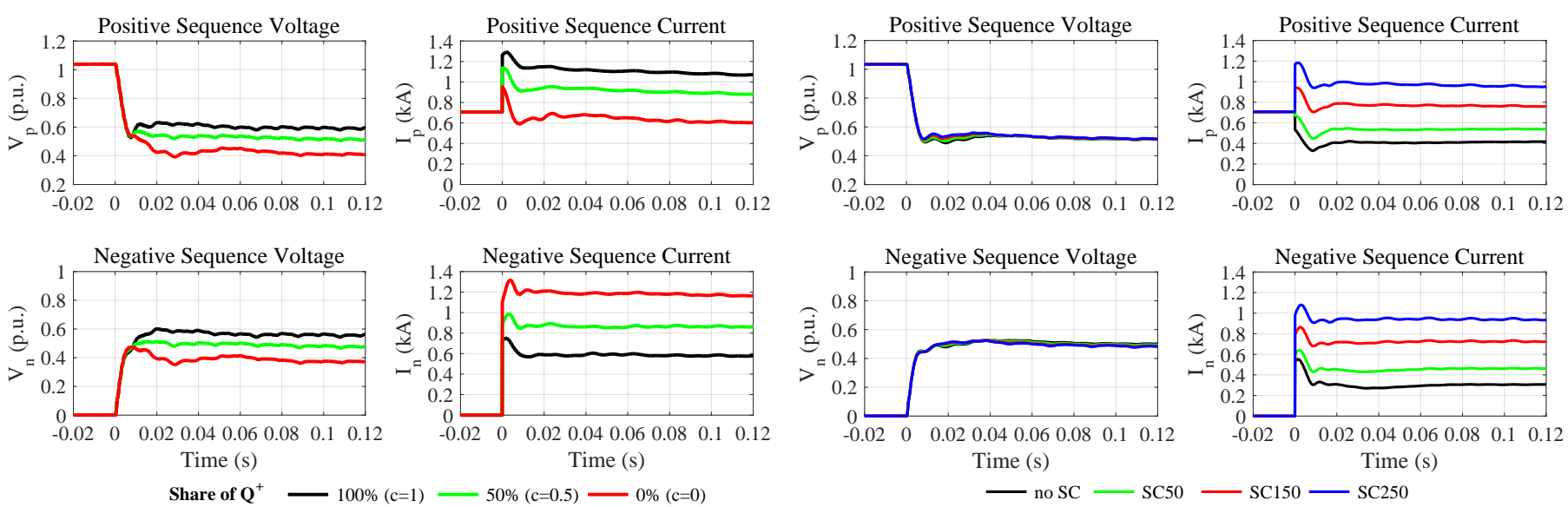

(a)
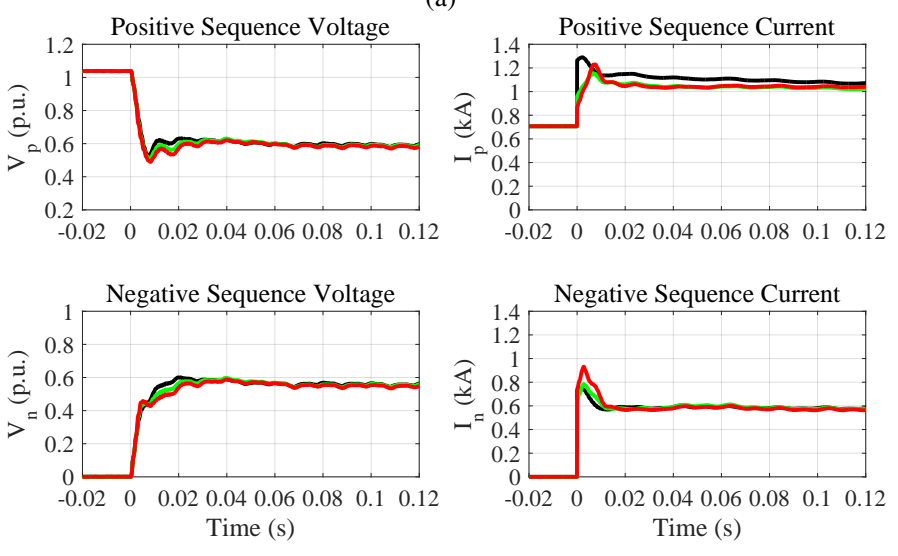

Share of $\mathbf{P}^{+}-100 \%(\mathrm{a}=1)$

(b)

Fig. 9. Comparisons on the sequence voltages at the PCC (bus 6) and sequence currents measured at $\mathrm{M}$ under different VSC1 (deploying FPNSPC) control strategies. (SC1: 250 Mvar) (a): $a=1,0 \leq c \leq 1$. (b): $0 \leq a \leq 1, c=1$

In Fig. 8(a), both positive- and negative-sequence voltages are increased when the control strategy moves from constant active power $(k=-1)$ towards balanced current control $(k=0)$, during which procedure the positive-sequence current is gradually increasing while the negative-sequence current reduces. As discussed in Section II, an increase of positivesequence reactive current helps to improve positive-sequence voltage and a reduction of negative-sequence reactive current deteriorates the negative-sequence voltage attenuation, which increases the negative-sequence voltage. Therefore, with $k$ shifting from -1 to 0 , the changes of both sequence currents in Fig. 8(a) have the same effect on the sequence voltages due to the mutual coupling between the positive- and negativesequence networks under phase-phase faults. On the other hand, with the control strategy changing from balanced current to constant reactive power control $(k=1)$, the changes in the sequence voltages are not obvious anymore in Fig. 8(b). As a result of the current cancellation problem discovered in Section IV-A, both positive- and negative-sequence currents are reducing during this procedure, in which the effect of reducing positive-sequence voltage and increasing negativesequence voltage counters each other.

In Fig. 9(a), both positive- and negative-sequence voltages are reducing with the share of $Q^{+}$changing from $100 \%$

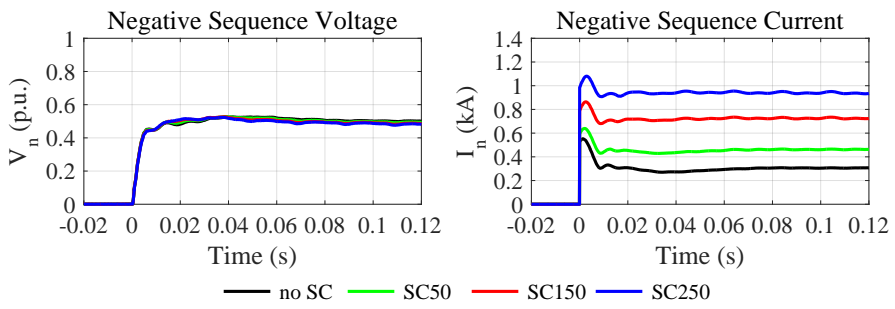

Fig. 10. Comparisons on the sequence voltages at the PCC (bus 6) and sequence currents measured at $\mathrm{M}$ under different $\mathrm{SC} 1$ capacities. (VSC1 deploys constant active power control)

towards $0 \%$. This is due to the fact that a reduction in positivesequence current and an increase in negative-sequence current have the same effect. Since the system in Fig. 4 is an inductive system, voltage support on the PCC is mainly achieved by reactive current and hence a change in $a$ (the share of $P^{+}$) has a less notable influence on the PCC voltages in Fig. 9(b).

Since most grid codes do not impose requirements on VSCs regarding the negative-sequence current provision, VSCbased sources are commonly controlled to provide only positive-sequence currents during unbalanced faults [20], [23]. Therefore, VSCs behave as open circuits in the negativesequence network and the negative-sequence voltage cannot be attenuated, which might lead to over-voltage problems in healthy phases. The examined control strategies affect the PCC voltages mainly through sequence reactive power. From this point of view, by moving the strategy from balanced current to constant active power control in FOPC, or having $c$ between 0 and 1 with FPNSPC, VSCs have the potential to help to attenuate negative-sequence voltages under grid unbalanced faults. Other control logic can be implemented to generated the exact values of $k$ or $c$ based on the needs of the grid.

Secondly, the combined effect with an SC on the PCC voltages is investigated. In this case, the capacity of SC1 is varied from 0 (disconnected from the grid) to 250 Mvar given a fixed VSC1 control strategy. As an example, the sequence voltages of the PCC and the sequence currents measured at point $\mathrm{M}$ with different capacities of SC1 are plotted in Fig. 10 when VSC1 deploys constant active power control. The short circuit current level in both positive- and negative-sequence networks are increased with a higher capacity of SC1. During grid unbalanced faults, synchronous condensers can inherently provide both positive- and negative-sequence reactive currents. The increase in the positive-sequence reactive current tends to support the positive-sequence voltage. However, an increase on the negative-sequence reactive current helps to attenuate the voltage unbalance, which in turn tends to reduce the positivesequence voltage. Therefore, $\mathrm{SC} 1$ does not alter the sequence voltages as notably as those in Fig. 8 and Fig. 9. This indicates that, once the control strategy of VSC1 is fixed, the application of SC1 has less impact on the PCC sequence voltages for 

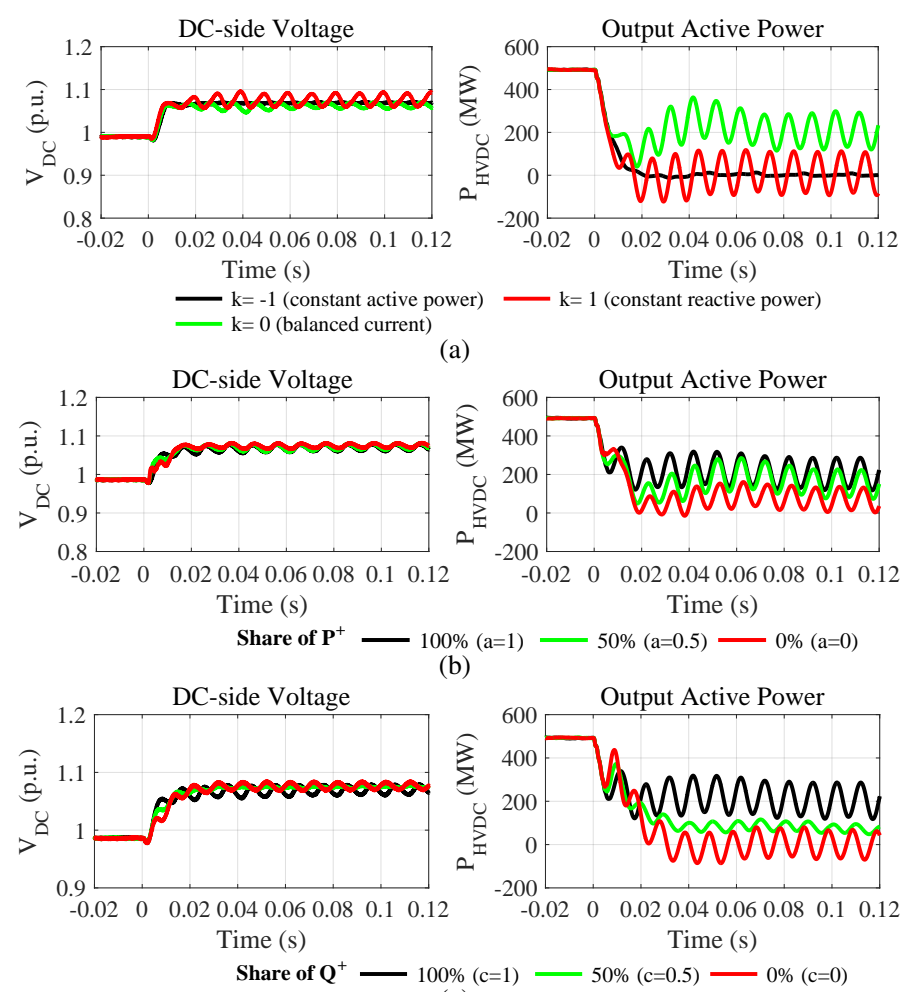

(b)

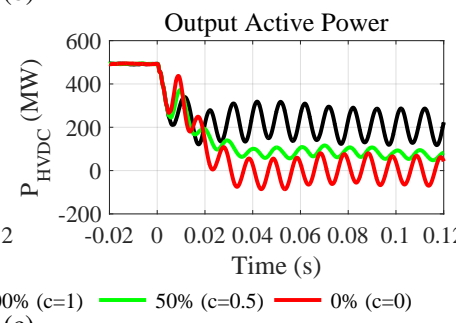

(c)

Fig. 11. Comparisons on the DC-side voltages and output active powers of VSC1 under different control strategies. (SC1: 250 Mvar) (a): FOPC, $-1 \leq$ $k \leq 1$. (b): FPNSPC, $c=1,0 \leq a \leq 1$. (c) FPNSPC, $a=1,0 \leq c \leq 1$.

unbalanced faults.

\section{DC-side Voltage}

Firstly, the control strategy factors of VSC1 are varied to examine the effect of the control strategies on the DC-side voltage given a fixed SC1 capacity. The corresponding DCside voltages and output active powers of VSC1 are plotted in Fig. 11. With reactive power provision prioritized and the current limit imposed, the active power from VSC1 is curtailed under fault conditions. This results in an increase in the DCside voltages. In Fig. 11(a), the amplitudes of the DC-side voltage oscillations, as well as output active power oscillations, are growing when the control strategy moves from constant active power control to constant reactive power control. When FPNSPC is deployed, a variation on the share of $P^{+}$does not have a notable influence on the amplitudes of the output active power oscillations in Fig. 11(b) and the DC-side voltage profiles are close to each other. However, with the share of $Q^{+}$ changing from $100 \%$ to $0 \%$, the amplitudes of the active power oscillations in Fig. 11(c) reduces first and then increases, giving the same trend in the DC-side voltage oscillations. These facts indicate that the DC-side voltage oscillations can be reduced by the injection of positive $Q^{-}$, while $P^{-}$does not have a notable effect. By moving the control strategy from balance current control to constant active power control in FOPC or choosing the share of $Q^{-}$between $100 \%(c=1)$ to $50 \%(c=0.5)$ in FPNSPC, the DC-side voltage oscillations can be reduced.
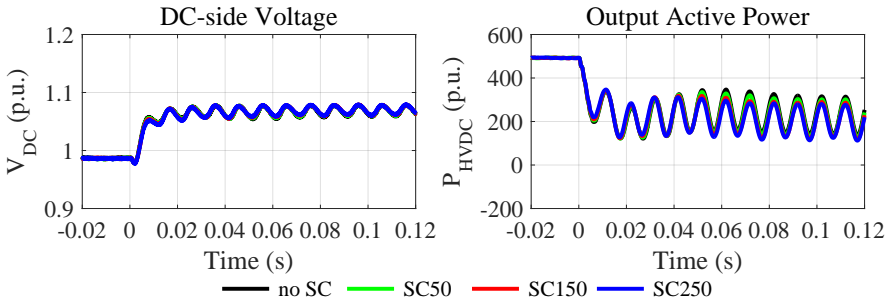

Fig. 12. Comparisons on the DC-side voltages and output active powers of VSC1 under different SC1 capacities. (VSC1 deploys balanced current control)
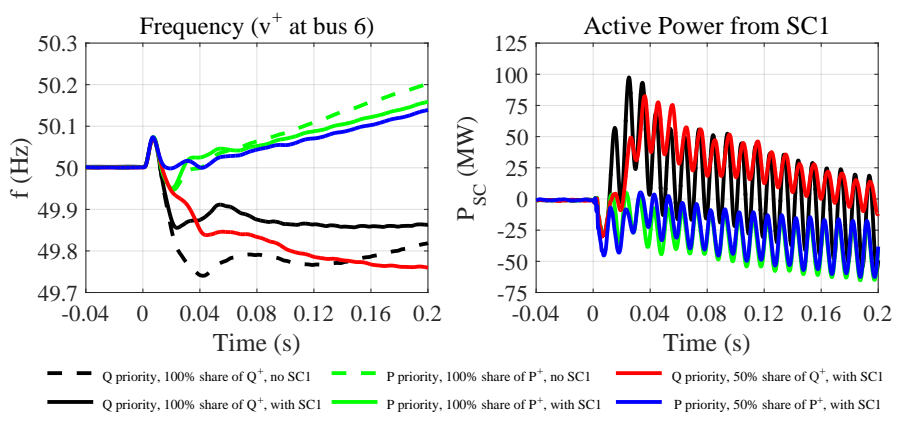

Fig. 13. Comparisons on the frequency responses at the PCC (using positivesequence voltages) and active powers of SC1 under different control strategies. (SC1: 250 Mvar)

Secondly, the capacity of $\mathrm{SC} 1$ is varied to examine the effect of an SC on the DC-side voltage given a fixed VSC1 control strategy. For example, when VSC1 deploys balanced current control, Fig. 12 compares the DC-side voltages and output active powers of VSC1 under different capacities of SC1. It can be observed that SC1 has almost no effect on the DC-side voltage under unbalanced faults regardless the presence or the capacity of SC1.

\section{E. Frequency Response}

This case study investigates the impact of a synchronous condenser and VSC1 control strategies on the system frequency responses under unbalanced faults. As a base scenario, with $\mathrm{SC} 1$ disconnected from the grid, the frequency responses of the positive-sequence voltage at the PCC (bus 6) are plotted in Fig. 13 with dashed lines. The VSC1 provides only positivesequence short circuit powers under unbalanced faults, with either active power provision prioritized (green-dashed curve) or reactive power provision prioritized (black-dashed curve). Then with a 250 Mvar SC1 connected to the grid, the frequency responses (black- and green-solid curves) are improved with less deviation from $50 \mathrm{~Hz}$. Since a synchronous condenser is a rotating machine, it provides inertia for the system to counter the frequency deviation.

Next, with the same SC1 connected, the control strategy of VSC1 is changed to either providing $50 \% Q^{+}(c=0.5)$ with $\mathrm{Q}$ priority or providing $50 \% \mathrm{P}^{+}(a=0.5)$ with $\mathrm{P}$ priority. The corresponding frequency responses are the redand blue-solid curves respectively in Fig. 13. In Fig. 1(c) where FOPC and FPNSPC are illustrated in an unified way, $(a, c)=(1,1)$ means VSC1 will only provide positivesequence short circuit power $\left(P^{+}\right.$and $\left.Q^{+}\right)$. If $(a, c)$ moves away from $(1,1)$, negative-sequence current will flow through 
TABLE IV

SUMMARY OF THE INVESTIGATION

\begin{tabular}{ccc}
\hline \hline Aspects & VSC control strategies & Synchronous condensers \\
\hline Short circuit current & Avoid $k>0$ with FOPC (could raise current cancellation problem); & $\begin{array}{c}\text { Help bring the phases and } \\
\text { amplitudes of the short circuit } \\
\text { currents close to those from } \\
\text { synchronous sources; }\end{array}$ \\
\hline PCC voltage & $\begin{array}{c}\text { (1) Affected by } Q^{+} \text {and } Q^{-} \text {rather than } P^{+} \text {and } P^{-} \text {for inductive grids; (2) The injection of } \\
\text { positive } Q^{-}(k<0 \text { with FOPC or } c<1 \text { with FPNSPC) helps attenuate negative-sequence } \\
\text { voltage; (3) The changes of positive- and negative-sequence currents have to be in opposite } \\
\text { directions to effectively change sequence voltages; }\end{array}$ & $\begin{array}{c}\text { Natural control on } \\
\text { sequence-voltages; }\end{array}$ \\
\hline DC-side voltage & $\begin{array}{c}\text { (1) The injection of positive } Q^{-}(k<0 \text { with FOPC or } 0.5<c<1 \text { with FPNSPC) helps } \\
\text { reduce DC-side voltage oscillations; (2) } P^{-} \text {has no notable effect }\end{array}$ & No notable effect; \\
\hline Frequency response & $\begin{array}{c}\text { (1) Affected by how much active power is curtailed; (2) For under-frequency, avoid the injection } \\
\text { of positive } P^{-}(k>0 \text { with FOPC or } a<1 \text { with FPNSPC); (3) For over-frequency, the } \\
\text { injection of } P^{-} \text {and } Q^{-} \text {in both directions helps counter frequency deviation; }\end{array}$ & Provide inertia for the system; \\
\hline \hline
\end{tabular}

VSC1. As shown in Fig. 11, the further $(a, c)$ moves away from $(1,1)$, the more active power VSC1 has to curtail to comply with the current limit. Therefore, the impact of the VSC1 control strategy on the system frequency responses is indeed a question of how much active power is curtailed. For a system experiencing under-frequency issues during the unbalanced fault, there is no need to have $a<1$. On the one hand, the injection of positive $P^{-}$will results in more active power to be curtailed. On the other hand, it neither helps with voltage support nor helps to reduce the DC-side voltage oscillations. For a system experiencing over-frequency issues during unbalanced faults, the injection of $P^{-}$and $Q^{-}$in both directions can help to reduce the frequency deviation.

\section{F. Summary}

Based on the above case studies, a summary of the investigations is provided in Table. IV. Regarding the combined short circuit current, FOPC with $k>0$ should be avoided as it tends to reduce the short circuit level when incorporating with synchronous condensers. In comparison, constant active power control (FOPC with $k=-1$ ) gives short circuit current similar to that of synchronous condensers in terms of the phases, and hence helps increase the total short circuit current level. The PCC voltage in an inductive grid is more affected by $Q^{+}$and $Q^{-}$rather than $P^{+}$and $P^{-}$. The injection of positive $Q^{-}$ ( $k<0$ with FOPC or $c<1$ with FPNSPC) can actively help reduce the voltage unbalance under unbalanced faults. On the other hand, the injection of positive $Q^{-}$also helps reduce the DC-side voltage oscillations. Since the oscillations of the DCside voltage are directly related to the oscillations of the VSC output active power, constant active power control is more suitable when DC-side voltage is a concern. The control strategy of VSC-based sources affects system frequency response in terms of how much active power is curtailed during the fault. Since the flow of negative-sequence powers $\left(P^{-}\right.$and $\left.Q^{-}\right)$ occupies the current margin left for active power injection, the control over negative-sequence powers has a potential to be used to improve the system frequency response as stated in Table IV.

As a result, the authors recommend constant active power control for VSC-based sources when incorporating synchronous condensers. This helps increase the short circuit current level, attenuate negative-sequence voltage, and reduce DC-side voltage oscillations at the same time. Even though this could lead to more active power from VSC being curtailed, the existence of the synchronous condenser provides inertia for the system to counter the frequency deviation under fault conditions.

\section{CONCLUSIONS}

With different control strategies, the short circuit responses of VSC-based sources under grid unbalanced faults are significantly different from that of synchronous condensers. Different control strategies could raise problems such as nonconventional characteristics of the short circuit current, a lack of negative-sequence reactive current, DC-side voltage oscillations and excess active power curtailment under fault conditions. The application of a synchronous condenser at the PCC helps to increase the short circuit level and bring the phases of the combined short circuit current close to that from a synchronous source. By providing positive- and negative-sequence reactive power simultaneously, synchronous condensers help to control sequence voltages naturally. As a rotating device, it can provide inertia for the system to counter the frequency deviation. Therefore, synchronous condensers are able to mitigate the disadvantages of certain control strategies. This study provides suggestions on the selections of the control strategies for a VSC-based source with the incorporation of a synchronous condenser at the PCC. Future work could be the optimal allocation of synchronous condensers and the design of their protection system.

\section{APPENDIX \\ SYSTEM PARAMETERS}

Line impedance

Line 1-2: $(1.47+\mathrm{j} 18.13) \Omega$; Line 2-3: $(0.85+\mathrm{j} 14.00) \Omega$; Line 2-4: $(0.85+\mathrm{j} 14.00) \Omega$; Line $3-5:(1.83+\mathrm{j} 22.57) \Omega$; Line $4-5$ : $(1.83+\mathrm{j} 22.57) \Omega$; Line $2-6:(0.65+\mathrm{j} 8.65) \Omega$

Transformer leakage inductance

T1: 8\%; T2: 11\%; T3: 10\%; T4: $8 \%$; T5: $11 \%$

VSC1 and VSC2 
Rated DC link voltage: $350 \mathrm{kV}$; Switching frequency: 1650 $\mathrm{Hz}$; DC link capacitor: $250 \mu \mathrm{F}$; Reactor inductance: $0.02 \mathrm{H}$; Proportional gain of current controllers: 0.4; Integrator time constant of current controllers: 0.03

\section{REFERENCES}

[1] H. Akagi, E. H. Watanabe, and M. Aredes, Instantaneous power theory and applications to power conditioning. Hoboken, NJ, USA: John Wiley \& Sons, Inc., 2006.

[2] F. Blaabjerg, R. Teodorescu, M. Liserre, and A. V. Timbus, "Overview of control and grid synchronization for distributed power generation systems," IEEE Trans. Ind. Electron., vol. 53, no. 5, pp. 1398-1409, Oct 2006.

[3] H. D. Tafti, A. I. Maswood, Z. Lim, G. H. P. Ooi, and P. H. Raj, "A review of active/reactive power control strategies for pv power plants under unbalanced grid faults," in Proc. 2015 IEEE Innovative Smart Grid Technologies - Asia (ISGT ASIA), Bangkok, Thailand, Nov. 2015, pp. 1-6.

[4] J. Jia, G. Yang, and A. H. Nielsen, "A review on grid-connected converter control for short circuit power provision under grid unbalanced faults," IEEE Trans. Power Del., vol. 33, no. 2, pp. 649-661, Apr. 2018.

[5] M. Guan and Z. Xu, "Modeling and control of a modular multilevel converter-based HVDC system under unbalanced grid conditions," IEEE Trans. Power Electron., vol. 27, no. 12, pp. 4858-4867, Dec. 2012.

[6] (2018, Dec.) The stable way-synchronous condenser solutions. [Online]. Available: http://www.energy.siemens.com/hq/pool/hq/ power-transmission/FACTS/Synchronous\%20Condenser/Synchronous_ Condenser.pdf

[7] M. Nedd, Q. Hong, K. Bell, C. Booth, and P. Mohapatra, "Application of synchronous compensators in the gb transmission network to address protection challenges from increasing renewable generation," in Proc. Cigre Study Committee B5 Colloquium, Auckland, New Zealand, Sep. 2017, pp. 1-6.

[8] S. Kynev, G. Pilz, and H. Schmitt, "Comparison of modern STATCOM and synchronous condenser for power transmission systems," in Proc. 2016 IEEE Elect.Power and Energy Conf. (EPEC), Ottawa, Canada, Oct. 2016, pp. 1-6.

[9] Y. Liu, S. Yang, S. Zhang, and F. Z. Peng, "Comparison of synchronous condenser and STATCOM for inertial response support," in Proc. 2014 IEEE Energy Convers. Congr. and Exposition (ECCE), Pittsburgh, PA, USA, Sep. 2014, pp. 2684-2690.

[10] F. O. Igbinovia, G. Fandi, Z. Müller, J. Švec, and J. Tlustý, "Optimal location of the synchronous condenser in electric-power system networks," in Proc. 2016 17th Int. Scientific Conf. on Electric Power Eng. (EPE), Pragure, Czech Republic, May 2016, pp. 1-6.

[11] M. Nambiar and Z. Konstantinovic, "Impact of using: synchronous condensers for power system stability and improvement of short-circuit power in mining projects," Mining Engineering, vol. 67, no. 1, pp. 3844, Jan. 2015.

[12] Nahid-Al-Masood, R. Yan, T. K. Saha, and N. Modi, "Frequency response and its enhancement using synchronous condensers in presence of high wind penetration," in Proc. IEEE PES General Meeting, Denver, CO, USA, Jul. 2015, pp. 1-5.

[13] P. E. Marken, A. C. Depoian, J. Skliutas, and M. Verrier, "Modern synchronous condenser performance considerations," in Proc. IEEE PES General Meeting, Detroit, MI, USA, Jul. 2011, pp. 1-5.

[14] Z. H. Rather, Z. Chen, P. Thoegersen, and P. Lund, "Dynamic reactive power compensation of large-scale wind integrated power system," IEEE Trans. Power Syst., vol. 30, no. 5, pp. 2516-2526, Sep. 2015.

[15] N. Masood, R. Yan, T. K. Saha, and S. Bartlett, "Post-retirement utilisation of synchronous generators to enhance security performances in a wind dominated power system," IET Gener, Transm. Distrib., vol. 10, no. 13, pp. 3314-3321, Oct. 2016.

[16] E. Marrazi, G. Yang, and P. Weinreich-Jensen, "Allocation of synchronous condensers for restoration of system short-circuit power," Journal of Modern Power Syst. and Clean Energy, vol. 6, no. 1, pp. 17-26, Jan. 2018.

[17] J. Jia, G. Yang, A. H. Nielsen, E. Muljadi, P. Weinreich-Jensen, and V. Gevorgian, "Synchronous condenser allocation for improving system short circuit ratio," in Proc. 2018 5th Int. Conf. on Electric Power and Energy Convers. Syst. (EPECS), Apr. 2018, pp. 1-5.

[18] R. Teodorescu, M. Liserre, and P. Rodríguez, Grid converters for photovoltaic and wind power systems. Chichester, UK: John Wiley \& Sons, Ltd., 2011.
[19] F. Wang, J. L. Duarte, and M. A. M. Hendrix, "Pliant active and reactive power control for grid-interactive converters under unbalanced voltage dips," IEEE Trans. Power Electron., vol. 26, no. 5, pp. 1511-1521, May 2011.

[20] T. Neumann, T. Wijnhoven, G. Deconinck, and I. Erlich, "Enhanced dynamic coltage control of type 4 wind turbines during unbalanced grid faults," IEEE Trans. Energy Convers., vol. 30, no. 4, pp. 1650-1659, Dec. 2015.

[21] A. A. van der Meer, R. L. Hendriks, and W. L. Kling, "Combined stability and electro-magnetic transients simulation of offshore wind power connected through multi-terminal vsc-hvdc," in Proc. IEEE PES General Meeting, Providence, RI, USA, Jul. 2010, pp. 1-7.

[22] Technical Regulation 3.2.5 for Wind Power Plants With a Power Output Above $11 \mathrm{~kW}$, Energinet, Fredericia, Denmark, Jun. 2015.

[23] Ö. Göksu, R. Teodorescu, C. L. Bak, F. Iov, and P. C. Kjær, "Impact of wind power plant reactive current injection during asymmetrical grid faults," IET Renewable Power Gen., vol. 7, no. 5, pp. 484-492, Sep. 2013.

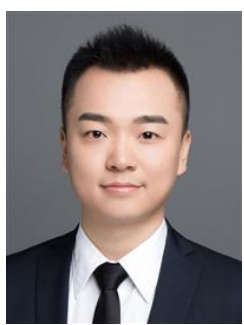

Jundi Jia (M'19) received the B.Sc. degree in electrical engineering and automation from Beijing Jiaotong University, Beijing, China, in 2012, and the M.Sc. degree in electric power engineering from KTH Royal Institute of Technology, Stockholm, Sweden, in 2014, and the Ph.D. degree in electric power system from DTU Technical University of Denmark, Konges Lyngby, Denmark, in 2018. In 2015, he was a Strategy Consulting Analyst on resource utilities with Accenture, Beijing, China. In 2017, he was a Visiting Researcher with the National Renewable Energy Laboratory, Golden, CO, USA. He was a Postdoc Researcher with the Center for Electric Power and Energy, Technical University of Denmark, Kongens Lyngby, Denmark in 2018. His research interests include power system dynamics and protection, power electronics, and integration of renewable energy. Currently, he is a Product Engineer with Vestas Wind Systems A/S, Aarhus N, Denmark.

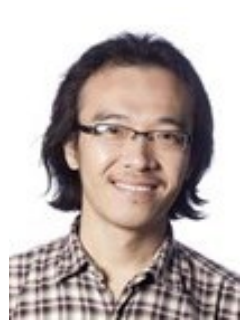

Guangya Yang (SM'14) received the B.E., M.E. degrees all in the field of electric power system from Shandong University, China, in 2002 and 2004, respectively and $\mathrm{Ph} . \mathrm{D}$. degree in electric power system from The University of Queensland, Brisbane, Australia, in 2008. Since 2009, he has been with the Technical University of Denmark, Kongens Lyngby, Denmark, as a Postdoctoral Researcher, and he is currently an Associate Professor with the Center for Electric Power and Energy, Department of Electrical Engineering, Technical University of Denmark, Kongens Lyngby, Denmark. Since 2009, he has been leading several industrial collaborative projects in Denmark in the field of monitoring, operation and protection of renewable energy systems. His research interests include renewable energy integration, smart grids, and cyber-physical energy systems.

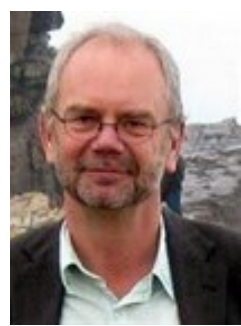

Arne Hejde Nielsen (SM'08) received M.Sc. degree in electric power engineering from Technical University of Denmark, Kongens Lyngby, Denmark, in 1978. He is an Associate Professor with the Centre for Electric Power and Energy, Department of Electrical Engineering, Technical University of Denmark, Kongens Lyngby, Denmark. He has 30 years of experience in electric power engineering; the first years were from ASEA AB, Central Research and Development Department, Sweden, with focus on measurement technology and motor design and control. Over the past decade, his focus has been on electric power systems, especially on the implementation of renewable energy sources in the power system. 


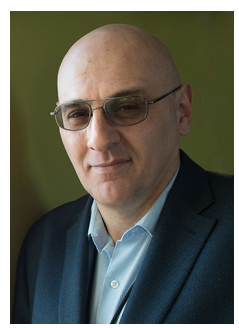

Vahan Gevorgian (SM'97) received the B.S. and M.S. degrees from the Yerevan Polytechnic Institute, Yerevan, Armenia, and the Ph.D. degree in electrical engineering from the State Engineering University of Armenia, Yerevan, Armenia, in 1993. He is a Chief Engineer with the National Wind Technology Center, National Renewable Energy Laboratory, Golden, $\mathrm{CO}$, USA. He is currently focusing on renewable energy impacts on transmission and interconnection issues and dynamic modelling of variable generation systems. He is a Member of the IEC team for wind turbine power quality standards. 